\title{
O romance de formação da professora: contribuições da literatura para pensar a História da Educação
}

The teacher education novel: contributions from literature to think about the History of Education

La novela de formación del profesorado: aportes de la literatura para pensar la Historia de la Educación

Patrícia Aparecida do Amparo

Universidade de São Paulo (Brasil)

https://orcid.org/0000-0003-1283-0901

http://lattes.cnpq.br/9039499699404230

patricia.amparo@usp.br

Renata Marcílio Cândido

Universidade Federal de São Paulo (Brasil)

https://orcid.org/0000-0002-8032-881X

http://lattes.cnpq.br/9931089607245261

renata.candido@unifesp.br

Ana Laura Godinho Lima

Universidade de São Paulo (Brasil)

https://orcid.org/0000-0003-4154-0858

http://lattes.cnpq.br/4941128584192341

alglima@usp.br

\section{Resumo}

Este artigo investiga os processos de formação docente descritos em dois livros publicados na primeira metade do século XX, a saber: "O calvário de uma professora", de Dora Lice, e "Clarissa", de Érico Veríssimo. Investe-se na leitura desses livros como romances de formação que ao apresentarem as personagens-professoras em diferentes circunstâncias, escolares e não escolares, permitem identificar os complexos processos que constroem suas identidades profissionais. As temáticas relacionadas à escolha profissional das protagonistas, as questões de gênero presentes nos enredos das obras, assim como os usos potenciais das obras literárias para tratar dos temas da história da educação brasileira, incluindo a história da escola, da profissão docente, e os embates entre o método tradicional e as ideias renovadas de ensino constituem eixos articuladores da análise aqui proposta.

Palavras-chave: Romances de formação. Fonte literária. Formação docente. 


\begin{abstract}
This article investigates the teacher training processes described in two books published in the first half of the 20th century, namely: "The calvary of a teacher", by Dora Lice, and "Clarissa", by Érico Veríssimo. We invest in reading these books as training novels that, when presenting the character-teachers in different circumstances, school and non-school, allow us to identify the complex processes that build their professional identities. The themes related to the professional choice of the protagonists, the gender issues present in the plots of the works, as well as the potential uses of literary works to deal with the themes of the history of Brazilian education, including the history of the school, the teaching profession, and the clashes between the traditional method and the renewed teaching ideas constitute articulating axes of the analysis proposed here.
\end{abstract}

Keywords: Formation novels. Literary source. Teacher training.

\title{
Resumen
}

Este artículo investiga los procesos de formación docente descritos en dos libros publicados en la primera mitad del siglo XX: "El calvario de una maestra", de Dora Lice, y "Clarissa", de Érico Veríssimo. Tomamos la lectura de estos libros como novelas formativas que, al presentar al personaje-docente en diferentes circunstancias, escolares y extraescolares, nos permiten identificar los complejos procesos que construyen sus identidades profesionales. El análisis propuesto tiene como ejes la elección profesional de los protagonistas y las cuestiones de género presentes en las tramas de las obras. También integran el análisis consideraciones sobre los usos potenciales de las obras literarias para abordar los temas de la historia de la educación brasileña, incluida la historia de la escuela, de la profesión docente y los enfrentamientos entre el método tradicional y las ideas pedagógicas renovadas.

Palabras clave: Novelas de formación. Fuente literaria. Formación de profesores. 


\section{Introdução}

Ao longo do século XX, a formação dos indivíduos foi concebida predominantemente como um processo de desenvolvimento "natural" da infância à idade adulta, a ser acompanhado e conduzido pela família no lar e as professoras na escola. Estabeleceu-se então uma associação entre o desenvolvimento da criança e o progresso social, que demandava estudos científicos e investimentos do governo nas questões relativas à sua saúde e educação, a qual ainda perdura nos discursos sobre a educação divulgados na grande imprensa. A questão da infância adquiriu importância política e as tarefas de cuidar e educar as crianças passaram a ser reconhecidas como atribuições socialmente relevantes. Contribuíram para isso o movimento higienista da primeira metade do século e a institucionalização da psicologia como ciência e como profissão, que tomaram a criança em desenvolvimento como objeto de estudos e intervenções. A ideia de que o futuro da pátria dependia da sobrevivência, da saúde e da boa educação das crianças fez com que se atribuísse importância à instrução das mães em matéria de puericultura e à formação profissional das professoras (FREIRE, 2008; FERREIRA \& GONDRA, 2006).

No período que correspondeu aproximadamente à Primeira República no Brasil, os esforços do governo relativos à educação das crianças se concentraram na estruturação dos sistemas públicos de ensino, que tomaram forma nos grupos escolares seriados onde se praticava o ensino simultâneo e nas escolas normais para a formação das professoras. Essas instituições se disseminaram lentamente pelo território brasileiro (SOUZA, 1998; CARVALHO, 1989). A partir da década de 1920, a atenção dos educadores se voltou para a questão dos métodos e uma série de reformas do ensino foram realizadas em diferentes estados, ao mesmo tempo em que se multiplicavam as publicações especializadas em educação (NAGLE, 1976; CARVALHO, 1989). Os princípios do movimento escolanovista orientaram as iniciativas dos reformadores e alcançaram maior evidência com a publicação do Manifesto dos Pioneiros da Educação Nova, de 1932, documento redigido por Fernando de Azevedo e assinado por diversos intelectuais da época. $\mathrm{O}$ Manifesto reivindicava a instituição da escola pública para todos, onde meninos e meninas estudassem juntos, uma escola laica, gratuita e obrigatória. Defendia ainda a renovação das práticas de ensino, fundamentadas nos novos conhecimentos da psicologia sobre as crianças e seu desenvolvimento (VIDAL, 2013).

Os livros O calvário de uma professora (1928) e Clarissa (1933) foram publicados nesse período de transição, e expressam tanto as deficiências percebidas no sistema de ensino e nas práticas escolares ditas tradicionais, consideradas pelos educadores escolanovistas como ultrapassadas, quanto apresentam algumas das ideias disseminadas no campo educacional à época acerca de como as escolas deveriam ser transformadas para favorecer o desenvolvimento dos alunos. O fato do livro $O$ calvário de uma professora ser um romance de caráter autobiográfico e Clarissa um romance ficcional é relevante e a diferença se evidencia nas perspectivas dos autores. A autora e professora Dora Lice sofreu na própria pele as dificuldades associadas às condições precárias do exercício do magistério do decorrer da Primeira República, assim como os efeitos da desigualdade de gênero, que se refletia na hierarquia das posições no sistema de ensino. No caso de Érico Veríssimo, trata-se de investigar o modo pelo qual um escritor que não vivenciou a docência se situa diante das questões formativas. Como já observaram Maria Helena Câmara Bastos e Maria Teresa Santos Cunha (2000), a representação da sociedade gaúcha no trabalho literário do autor inclui diversos elementos da vida escolar e da profissão docente, os quais são amplamente explorados na composição dos contextos vividos por seus personagens. 
Apesar das diferenças, ambos podem ser aproximados ao gênero romance de formação ou Bildungsroman ${ }^{1}$, na medida em que acompanham o processo de edificação da personalidade das protagonistas, as quais, a partir das experiências vividas e das relações que estabelecem com outras pessoas, descobrem a si mesmas e vêm a ocupar um lugar no mundo. O que se coloca em primeiro plano, portanto, é o estudo literário a respeito de como se elaboram as potencialidades humanas, o desenvolvimento de suas possibilidades, gerando diversas interpretações do conceito desde o século XVIII. Poderíamos mencionar aquela de Georg Lukács, compreendendo o romance de formação como "...necessidade formal de que a reconciliação entre interioridade e mundo seja problemática mas possível” (p. 138); ou a definição de Mikhail Bakhtin, para quem este gênero literário apresenta “...os problemas da realidade e das possibilidades do homem e a questão da iniciativa criadora" (p.223). Se as diversas interpretações do gênero foram prolongando sua relevância como forma de investigar como alguém se forma, elas também estiveram comumente relacionadas ao processo formativo masculino e eurocêntrico. No entanto, compreensões mais alargadas do gênero têm associado o romance de formação a outros espaços e sujeitos. Estudos têm evidenciado sua potencialidade para falar sobre a posição feminina em Moçambique, como é o caso de Cíntia Acosta Kutter (2018), ou no Brasil, como faz Cristina Ferreira Pinto (1990). Este artigo, nesse sentido, busca se aproximar de tais iniciativas, identificando a fertilidade do romance de formação para compreender processos educativos femininos e professorais. Pode-se compreender, assim, certas singularidades das experiências de mulheres no mundo. Como observa Cristina Ferreira Pinto, em se tratando de protagonistas mulheres, deve-se levar em conta que as restrições socialmente impostas às mulheres se refletiram na caracterização das personagens femininas, cujo desenvolvimento era retratado apenas até o ponto em que atingiam a idade para casar e ter filhos. No caso dos livros que serão analisados neste artigo, o destino de professora se apresenta como a escolha de profissionalização "natural" para as mulheres e não como resultado de uma decisão pessoal, o que se evidencia mais claramente no caso da protagonista Hermengarda, de $O$ calvário de uma professora, que desejava ser médica, mas, em razão das adversidades econômicas enfrentadas por seu pai, precisou se resignar ao magistério.

Ao retratar o processo de formação da professora, portanto de quem se ocupa da formação das novas gerações, os romances que serão objeto de análise constituem um caso especial de romances de formação, ao enfatizarem processos de conciliação conflituosa entre mulheres e o mundo a sua volta, entendendo-se afinal como professoras. Consideramos que a leitura desses dois livros lado a lado oferece elementos valiosos para a compreensão da história da educação brasileira no período inicial de disseminação da escola pública e da divulgação do ideário da Escola Nova no Brasil, como se verá a seguir.

\section{Um escritor pensa sobre a formação: uma incursão à Clarissa, de Érico Veríssimo}

Em meio à prolífica produção de Érico Veríssimo (1905-1975), podemos identificar o compromisso do autor com a representação de diferentes personagens que compuseram os ambientes urbanos privilegiados em seu projeto literário. Entre eles, o escritor gaúcho criou personagens professores, como é o caso de Clarimundo, em Caminhos Cruzados, livro de 1935, e Clarissa, obra originalmente publicada em 1933, cuja protagonista é personagem

\footnotetext{
${ }^{1}$ De acordo com Cristina Ferreira Pinto, “A tradição do 'Bildungsroman' começa com o Wilhelm Meisters Lehrjahre de Goethe, publicado na Alemanha entre 1794 e 1796, e traduzido para o inglês em 1824 com o título de Wilhelm Meister's Apprenticeship (Buckley, 9-10). O termo alemão "Bildung" tem o sentido de formação, educação, cultura ou processo de civilização, e em português "Bildungsroman" seria traduzido como "romance de aprendizagem', 'de formação', ou 'de desenvolvimento"” (1990, p. 9). Desde sua criação no século XVIII, o gênero foi descrito a analisado por diversos autores, assim, variadas nomenclaturas foram estabelecidas. Mikhail Bakhtin (2011), por exemplo, utiliza o termo "Romance de educação", enfatizando os efeitos e apropriações do tempo histórico na formação humana.
} 
recorrente na produção de Veríssimo, surgindo também em outros títulos escritos nos anos 1930, a saber: Música ao Longe, de 1935, Um lugar ao Sol, de 1936, e Saga, já em 1940. A recorrência, sobretudo de Clarissa, representada nos livros supracitados em diversos momentos da formação e exercício profissional, indica o interesse do autor pela questão educacional e, ao mesmo tempo, a apropriação de diversos discursos a respeito da escola e da formação em circulação na primeira metade do século XX. Esse interesse também se manifesta nas incursões do autor pela literatura infantil, especialmente em livros como $\mathrm{Meu}$ $A B C$ e Aventuras no mundo da higiene, escritos para serem utilizados nas escolas. $\mathrm{O}$ segundo título mostra claramente a sintonia entre a literatura e o discurso higienista que se disseminava na sociedade da época, com efeitos substantivos no campo educacional, aproximação que já foi bem examinada no texto Infância, Higiene \& Educação, de Maria Helena Câmara Bastos e Maria Stephanou (2005).

Neste texto, por meio de uma análise do livro Clarissa e de incursões pontuais a passagens dos outros títulos em que a personagem aparece, pretende-se identificar o modo pelo qual o autor representa a formação docente ao se apropriar das preocupações educativas do período. Os livros em que a professora personagem aparece foram publicados predominantemente nos anos 1930, década marcada por intensas discussões e proposições educacionais atreladas à intenção de renovação da escola e das práticas de ensino (VIDAL, 2010). Não podemos desconsiderar que o Manifesto dos Pioneiros da Educação Nova fora publicado em 1932, portanto, um ano antes de Clarissa ir à público, gerando intensos debates após ampla divulgação na grande imprensa, como informa Diana Vidal (2013), que ainda acrescenta o interesse dos pioneiros na criação de um discurso estruturante das discussões educacionais a partir dele. Não se pode ignorar, portanto, que Érico Verissimo estava influenciado por esse contexto ao escrever um livro cuja personagem principal é uma jovem menina que está se tornando professora. As opções literárias e peripécias nas quais Clarissa se vê envolvida indicam, no entanto, uma apropriação do autor em que ele não apenas dialoga com os temas predominantes no período, mas também inclui em suas obras pontos de vista próprios, o que torna relevante investigar na produção do autor uma das formas de se pensar e projetar a educação brasileira na primeira metade do século XX.

Se Érico Veríssimo oferece um ponto de vista original a respeito da questão educacional por meio do texto literário, isso ocorre porque, segundo o historiador Nicolau Sevcenko (1983), a literatura oferece a linguagem organizada na forma de um discurso marcado pelas regras de seu lugar de produção e, assim, faz emergir as estruturas sociais de que emanam. Nesse sentido, como afirma Pierre Bourdieu (1998) ao falar d'A educação sentimental de Flaubert, uma análise da estrutura da obra permite ver a estrutura do espaço social em que o próprio autor está situado. Desse modo, convém mencionar que Érico Veríssimo nasceu no Rio Grande do Sul, oriundo de família rica e tradicional, porém em decadência, levando-o à ocupação de funções como a de bancário e lojista de farmácia, sendo assim, a produção do escritor parece ter se construído a partir desta perspectiva, pois seus livros estarão sempre muito marcados por temas urbanos através da observação das classes médias, como observa Alfredo Bosi (1997). Os livros publicados nos anos 1930, especialmente, ao acompanharem o desenvolvimento de Clarissa e Vasco, personagem masculino recorrente nesse ciclo da produção do autor, revelam esse interesse literário. Ao partirmos da hipótese segundo a qual a literatura pode ser fonte para a história da educação conforme registre um universo literário que representa o universo histórico social habitado por seu escritor, não poderemos desconsiderar, portanto, que as representações do espaço social e da circulação de Clarissa por ele revelam o ponto de vista do escritor a respeito de momento crucial para a história da educação brasileira. 


\section{A professora situada em seu tempo}

Ao construir a personagem Clarissa, nascida em Jacarecanga, uma cidade fíctícia no interior do Rio Grande do Sul, cuja família está passando por um processo de decadência econômica, Érico Veríssimo recorre à observação atenta do ano em que a jovem de 13 anos vai morar na capital para estudar e se transforma pelo contato com esse mundo novo. Ao optar por essa construção literária, identifica-se que a obra é construída a partir de alguns elementos que o aproximam de um Bildungsroman, isto é, de um romance de formação (PINTO, 1990). Apesar de não podermos definir o livro em análise como um romance de formação perfeito, ele apresenta alguns elementos desse gênero literário, uma vez que Érico Veríssimo quer registrar esse momento especial, talvez mágico, de transformação como afirma no prefácio à edição de 1973:

Desejei saber compor música para traduzir em melodia aquele momento poético; ou então pintar, para prender numa tela as imagens daquele minuto milagroso. [...] Foi então que me veio a sugestão de escrever a história duma menina que amanhece para a vida, pois talvez dessa forma eu pudesse prolongar o sortilégio daquele momento (VERÍSSIMO apud MORAIS, 2010, p. 43).

Trata-se de colocar em evidência as situações e circunstâncias de crescimento de uma menina que está se tornando professora. Ocorre que o livro situa a personagem que o nomeia em diversas situações, muitas vezes não escolares, em que ela vai amadurecendo, especialmente, aquelas que a fazem tomar contato com os tipos e circunstâncias que caracterizavam a sociedade dos anos 1930. Observa-se, assim, que o processo formativo descrito pelo autor está em diálogo com seu projeto literário, marcado por uma abordagem sociológica na elaboração da linguagem literária. Donizeth Santos afirma que Veríssimo buscava "... elaborar uma literatura que revelasse a engrenagem social e seus mecanismos, de modo que mostrasse o homem na sua dinâmica social e o indivíduo em sua humanidade, ou seja, que os seres humanos fossem apanhados em pleno ato de viver" (SANTOS, 2014, p. 331).

Ao fazer parte do modernismo literário, o escritor encontrou ferramentas para a construção de uma perspectiva crítica da sociedade ao tramar as ações de suas personagens (BOSI, 1997). Desse modo, Clarissa é descrita em meio a um conjunto de circunstâncias que a permitem conhecer diferentes tipos a compor a sociedade. Consequentemente, a personagem mantém uma relação circular com a realidade, que impulsiona suas reflexões e, a seguir, passa a compor sua subjetividade, auxiliando-a a ver o mundo. Assim Veríssimo define o movimento formativo. A estudante é constituída em meio a uma diversidade de pessoas e situações, apesar de elas afetarem-na em diferentes níveis de acordo com a proximidade ou distanciamento de suas preocupações. Entende-se que por meio desse recurso o autor impõe seu projeto literário às reflexões educativas. A esse respeito, pode-se observar um certo contraponto do autor ao discurso predominante dos anos 1930, o qual delimita os esforços de formação dos professores em uma preocupação com a aprendizagem dos alunos, situando a psicologia como referência fundamental para isso. Nas formulações do escritor, a professora em formação deveria ter como referência a sociedade, portanto, os conhecimentos acerca da realidade concreta, constituídos na experiência.

É desse modo que a jovem observa a variedade de personalidades na pensão de sua tia, onde mora e divide o espaço com outros tipos. Na pensão moram Major Pombo, Amaro, um músico entristecido que observa invejoso o feliz desabrochar de Clarissa, D.Eufrásia, proprietária do lugar, além de Belmira, descrita como Mulata. Nesse ambiente, Clarissa escuta conversas sobre aspectos da política, da história e tensões 
sociais: "De novo? Nada. A vida rola... Ameaças de guerra na Europa. Um discurso de Mussolini. Inundações na China. Crimes. Campanha eleitoral nos Estados Unidos. No Brasil - 'isto o que o senhor está vendo"”. (VERÍSSIMO, 1976, p.7).

No entanto, a temporalidade da vida de Clarissa é outra. Ela ouve sobre essas questões como quem escuta uma música ao fundo. Os aspectos da realidade que lhe interessam são aqueles que afetam seu cotidiano ou que se ligam às suas preocupações de menina. Assim, no caminho da casa até o colégio, ela vê o mundo e se encanta com alguns de seus aspectos:

A rua está animada. Nas portas das lojas de fazendas as pontas soltas das peças de seda voam como rútilas bandeiras. Passam homens e mulheres e crianças e cachorros. Na porta dum armazém um guri sardento trinca com dentes miúdos e aguçados uma rapadura de Santo Antônio da patrulha: o queixo todo melado, os olhos lambuzados de prazer (VERÍSSIMO, 1976, p.11).

Em tais circunstâncias, Clarissa olha para fora, mas também se vê:

Agora ela percebe que o vidro da vitrina espelha o seu rosto moreno em cujos lábios vermelhos e úmidos cintilam estrelinhas de sol. Dá um passo à retaguarda e mira-se no vidro com mais atenção. Um encantamento! Ela tem a impressão de que a sua imagem penetrou na vitrina, vaga e apagada como um fantasma, e como o aquário lhe fica à altura do peito, parece que o peixinho nada ao redor de seus seios: - tudo assim engraçado e impossível como em certos sonhos confusos que a gente sonha... (VERÍSSIMO, 1976, p.12).

Por meio de sua imagem refletida no espaço externo, a jovem pode se observar, de alguma forma, reconhecer sua própria imagem misturada às figuras refletidas dos objetos, animais, pessoas. O seu reflexo permite, na verdade, uma volta a si:

Vai para frente do espelho. Aproxima-se bem do cristal. É com ternura que se examina. Olha-se bem nos olhos, apalpa-se e num acesso de ternura começa a beijar os próprios braços, quase com gulodice, com uma vontade estranha de mordê-la (VERÍSSIMO, 1976, p.61).

Por meio das descrições da futura professora diante do espelho, Veríssimo nos indica a chave de sua interpretação acerca do amanhecer da professora. Trata-se de um caminho construído entre a realidade e sua interpretação individual. Nesse caminho, não interessam os grandes acontecimentos ou personagens, mas sim os aspectos da vida exterior que estão próximos de sua experiência em um determinado momento. O tempo é matéria de formação, assim Clarissa constrói sua história ao tomar o presente nas mãos. Ela não se importa com os grandes acontecimentos da História. A vida se cria no cotidiano como um trabalho artesanal e essa produção é feita todos os dias, permitindo a coleção de elementos e vivências constitutivas. Como diz Walter Benjamin "a história é objeto de uma construção cujo lugar não é o tempo homogêneo e vazio, mas um tempo saturado de agoras" (BENJAMIN, 1994, p.230). Os agoras de Clarissa, quando ela se depara com os outros, com as lojas, a escola, seus próprios desejos constituem matéria formativa. Este parece ser, também, o limite das possibilidades de integração aos elementos mais críticos do desenrolar histórico ou das tensões sociais permitidos, no projeto formativo de Veríssimo, à Clarissa. Em alguns momentos do livro ela é, inclusive, descrita como 
inocente por sua tia, tendo suas observações acerca da realidade circunscritas aos seus pensamentos (MORAIS, 2010). Essa construção da personagem difere muito das atitudes de Vasco, com quem a moça irá se casar, que tomou partido dos conflitos sociais, participando de uma guerra.

\section{A professora já foi aluna}

O modo pelo qual a jovem estudante se aproxima da sociedade de modo a constituir seu amanhecer pessoal também corresponde ao ângulo de visão por meio do qual ela observa a escola. Se, por meio dos outros livros em que aparece, vemos Clarissa exercendo a docência, o livro que a toma como protagonista demonstra sua trajetória de aluna e, assim, identificamos correspondências entre o amanhecer para a vida e a consolidação de uma relação com a instituição escolar. Na posição de aluna, a jovem não gostava de frequentar a escola, o que gera intensas reclamações de sua parte quando é obrigada a ir ao Colégio. É como se a instituição atrapalhasse a formação da garota, que requer a possibilidade de um contato direto com os elementos constitutivos do seu entorno reelaborados internamente, como também observa Roselusia Teresa Pereira de Morais (2010). Nesse sentido, não há sequer uma descrição das aulas e a instituição de ensino é representada do seguinte modo:

Como a vida é boa! E como seria mil vezes melhor se não houvesse esta necessidade (necessidade não: obrigação) de ir para o colégio, de ficar horas e horas curvada sobre a classe, rabiscando números, escrevendo frases e palavras, e aprendendo onde fica o Cabo da Boa Esperança, quem foi Tomé de Souza, em quantas partes se divide o corpo humano, como é que se acha a área de um triângulo... (VERÍSSIMO, 1976, p.10).

A escola é o espaço que aparta a aluna da vida, sendo assim o livro, de alguma forma, questiona os conteúdos da ação pedagógica. Ao construir tal perspectiva da escola, Veríssimo coaduna com a crítica escolanovista às práticas de ensino, entendidas como repetitivas e distantes dos estudantes. Assim, o discurso de renovação do ensino defendia práticas de ensino que as crianças e jovens pudessem observar e experimentar para construírem seus conhecimentos (VIDAL, 2010). Clarissa recupera essa discussão, questionando o significado de Tomé de Souza ou a localização do Cabo da Boa Esperança para a menina. Esse tempo dos grandes personagens e eventos por vezes repetido pelo currículo escolar é tensionado pelo cotidiano:

O primeiro governandor-geral do Brasil foi Tomé de Souza. Mas se tivesse sido o Major Nico Pombo, por acaso o sol deixaria de brilhar como agora? Existe um cabo que se chama Finisterra. Mas se não existisse, os jacarandás nãos estariam floridos do mesmo jeito? (VERÍSSIMO, 1976, p.12)

Na proposta literária de Veríssimo, a constituição dos sujeitos ocorre por meio dos acontecimentos miúdos, que permitem a elaboração pessoal do tempo e do passado. Assim, esses conhecimentos ensinados em momento de maior formalização da instituição escolar tensionam a liberdade de viver e aprender em favor da proposta escolar de se viver na escola para aprender o que ela tem a ensinar. Do ponto de vista criado pelo autor, o elo entre a escola e o aprendizado deve ser a própria vida social e uma reflexão a respeito dela e não necessariamente os saberes psicológicos, os quais ganham centralidade no período. Diante disso, para o autor, existe certa artificialidade na instrução escolar que se torna evidente quando 
Clarissa tem que estudar em casa:

Geografia. Matéria cacete. Decorar, decorar, decorar... E uma noite tão bonita lá fora!

O maciço montanhoso de leste é formado de terras atiquíssimas que os agentes naturais têm nivelado ao estado de planaltos.

Clarissa lê e relê o período. Fecha o livro e os olhos e procura repetir de cor o trecho lido. Os seus lábios se agitam levemente, as palavras lhe saem da boca num sussurro:

O maciço montanhoso de leste....

Detém-se. E depois? Abre o livro:

O maciço montanhoso de leste é formado de terras antiquíssimas... Ah! Agora sim. O maciço montanhoso de leste é formado de terras antiquíssimas... Mas por que antiquíssimas e não antiguísssimas? - que os agentes naturais.... - Mas que agentes naturais são esses? Eu conheço o agente do correio de Jacarecanga, que é o seu Moreira. Agentes naturais.... Que é isso? A gente nem entende nada, como é que vai aprender? - ... e reduzido ao estado de planaltos... - estado de planaltos? Estado.... estado do Rio Grade do Sul... estado do Sergipe... estado lastimável, como diz o tio Couto....

$\mathrm{O}$ relógio bate nove e meia. Clarissa ergue a cabeça. Por que será que os ponteiros não correm mais ligeiros? (VERÍSSIMO, 1976, p.41)

A aula está distante das referências que a estudante carrega consigo, as quais se constroem por meio de suas experiências e das possibilidades de apreensão dos conteúdos de ensino. É como se eles não pudessem fazer parte do amanhecer para a vida que as pessoas, situações vividas, animais e plantas, quando conhecidos diretamente, poderiam evocar. É como se a instituição escolar, na produção de Veríssimo, fosse um agente de cisão entre o tempo denso da experiência, daquele constituído pelo saber formal, visto como artificial quando se toma a vida como referência. Mais tarde, quando se torna professora, vemos que tais inquietações resultaram em posturas docentes descritas por ela em seu diário:

D. Ermelinda, a diretora do Elementar, continua implicante. Hoje ela me disse com sua voz seca: 'Clarissa, precisas fazer umas preleções cívicas aos teus alunos'. Ora, preleções cívicas! Os coitadinhos não entendem nada desses assuntos de pátria, de bandeira, de civismo. $\mathrm{O}$ que eles querem é brincar”. (VERÍSSIMO, 2005, p.97)

Ao escrever Clarissa, Érico Veríssimo indica que a educação escolar ajuda a amanhecer, no sentido proposto pelo autor, quando permite aproximar as referências pessoais e as situações em que se vive aos conteúdos de ensino. Essa perspectiva parece se aproximar da maneira como Anísio Teixeira, ao comentar a obra de John Dewey, descreve a educação, compreendida como: “(...) processo de reconstrução e reorganização da experiência, pelo qual lhe percebemos mais agudamente o sentido, e com isso nos habilitamos a melhor dirigir o curso de nossas experiências futuras" (TEIXEIRA, 1965, p.17)

A educação deveria, portanto, minimizar a oposição entre o "eu' e o "objeto", pois a integração de ambos permite o desenvolvimento do indivíduo. Para Dewey, é exatamente a identificação entre ambos que possibilita o interesse na educação. Já Veríssimo, ao trazer as dimensões da apropriação do tempo na experiência individual, chama atenção para o fato de essa identificação, de alguma forma, permitir a elaboração de uma relação com o tempo também 
constitutivo do amanhecer pessoal que deve articular uma reflexão crítica da sociedade. Não é sem motivo que o autor reforça a importância de registrar um momento específico de elaboração pessoal, o que permite ao leitor que é professor refletir sobre essas questões do ponto de vista do esforço educativo.

Ao organizar uma hipótese sobre a educação, Érico Veríssimo ofereceu uma possibilidade de se pensar a respeito das questões ligadas ao tema. Ao produzir tal interpretação literariamente, o autor inventou um ponto de vista particular a respeito da educação, de modo geral, e da formação de professores, de modo particular. Ao referenciar os discursos de renovação da educação na primeira metade do século XX, o escritor criou um ponto de vista sobre o tema de acordo com seu projeto literário e seus posicionamentos sociais em que os enunciados de modernização das práticas de ensino e da forma escolar ficaram atrelados à ideia do atravessamento da história e das questões sociais do presente. Nesse sentido, a professora amanhece para a vida e passa por processos formativos conforme associa sua postura pedagógica a uma percepção crítica das tensões sociais e políticas de seu entorno. Ademais, a escolha pela representação da professora amanhecendo pelo recurso aos elementos do romance de formação possibilitam articular e, de alguma forma, defender a ideia de formação docente ocorrendo em diferentes instâncias e tomando a profissional em dimensões variadas, como as sociais, políticas e de gênero.

\section{O calvário de uma professora e a "nobilíssima carreira do magistério": alguns elementos para análise da profissão e do trabalho docente}

A essa classe de quem tudo se espera, a quem tudo se pede e a quem nada se dá, concedei o vosso apoio, a vossa justa proteção. Porque é a personalidade da professora o mais importante elemento na educação da infância, é ela quem mais coopera na grande obra da formação do caráter nacional (LICE, 1928, p.04).

O texto de Dora Lice faz-se pertinente para tratar não somente das problemáticas do campo educacional sob o ponto de vista histórico, mas também para evidenciar o potencial formativo das experiências de si e do outro por meio do uso das obras literárias. O livro é bastante conhecido no meio acadêmico, objeto de teses e dissertações, utilizado como fonte e objeto de estudo ${ }^{2}$, constituindo-se leitura recomendada, quase obrigatória, aos pesquisadores da área da história da educação, que buscam conhecer melhor a organização do sistema público de ensino e da carreira docente no primeiro período republicano. Nesse contexto, o uso das histórias de vida aparece como recurso para pensar sobre a instituição escolar, suas práticas e cultura, seja a partir de relatos orais ou escritos: "refletir sobre a instituição escolar enquanto lugar de homogeneização dos comportamentos e sobre o espaço aberto para as diferenças nas relações entre os indivíduos" (CATANI, 1997, p. 16).

A leitura do texto possibilita sentimentos de encantamento e tristeza. O encantamento dá-se pela oportunidade de conhecer os bastidores da organização de um sistema público de ensino, desvelar o que os textos oficiais, as leis e decretos não dizem, compreender como se forja uma professora normalista nos primeiros anos da República Brasileira, momento no qual se divulgava a instituição escolar como a pedra angular do

\footnotetext{
${ }^{2}$ A dissertação de Mestrado de Dislane Zerbinatti Moraes (1996), intitulada Literatura, memória e ação política: uma análise de romances escritos por professores paulistas, analisa o romance $O$ calvário de uma professora e mais outros três romances escritos por professores no período entre 1920 e 1935, com o intuito de investigar as formas pelas quais estes profissionais conceberam a profissão, a carreira docente e a realidade escolar, suas práticas e representações, no período considerado para estudo.
} 
projeto republicano para a nação brasileira. E, de tristeza relacionada à percepção das agruras vividas pela protagonista, pelas injustiças sociais denunciadas por ela e pelas péssimas condições de vida enquanto profissional, esposa e mãe. Neste sentido, as questões que se configuram inicialmente e que pretendem nortear a retomada dessa obra relacionam-se ao modo como a história de vida de Hermengarda permite-nos pensar questões a respeito não somente da formação individual, mas também daquelas/daqueles que participaram dos processos de escolarização de outros indivíduos. Neste sentido, a escolha do livro fez-se não somente pelo fato de ele ser uma referência importante para o campo educacional, mas também pelas alterações que podem promover sobre a visão de escola, de sistema de ensino, de profissão e carreira docente.

Antes de prosseguir com o comentário do livro, cabe um breve parêntese. Sabe-se que, assim como Bourdieu em seu texto "A ilusão autobiográfica" (1998) a narrativa de vida submetida a uma seleção de acontecimentos pode não se constituir num documento que corresponda ao que, de fato, ocorreu na realidade. Trata-se de um texto ficcional, de uma reconstrução literária sobre um conjunto de fatos que pode se aproximar ou não da realidade vivida, que pode reproduzir episódios imaginários ou reais, uma história idealizada ou concreta, mas que de todo modo não invalida seus usos como fonte e objeto de pesquisa. Tendo em vista o processo complexo de elaboração das memórias individuais e coletivas, cabe dizer que os destaques feitos ao livro estão condicionados tão somente às relações subjetivas que estabelecemos com o mesmo e, muito pouco com a busca de uma pretensa verdade da obra.

\section{A autora, a protagonista e a professora}

A edição do texto utilizada para este artigo está organizada em 240 páginas, em formato mimeografado, possui algumas páginas mais e outras menos legíveis e é escrito na grafia da época, escrita por Violeta Leme sob o pseudônimo de Dora Lice, a obra foi publicada em 1928 pelo Estabelecimento Gráfico Irmãos Ferraz, que também editava revistas de ensino. Logo no início da obra, Dora Lice toma o cuidado de advertir os leitores de que "Os fatos aqui narrados são autênticos, apenas para o bom andamento da narrativa, não obedecem a ordem cronológica" (p. 03). Porém, é possível perceber a reconstrução dos primeiros passos da professora na carreira e, a sensação de que os fatos autobiográficos se fundem aos ficcionais é permanente no decorrer da leitura. A autora atuou como professora do ensino primário em várias escolas do interior de São Paulo e da capital entre os anos de 1905 e 1935, teve sete irmãs, quatro delas professoras, foi Vice-Presidente da Cruz Vermelha de Itatiba e, em 1918 participou ativamente do atendimento às vítimas da gripe espanhola. Seu livro, inicialmente publicado sob pseudônimo é reeditado em 1952, momento no qual se revela a verdadeira autoria do texto (MORAES, 2019).

Dos passos iniciais da protagonista na carreira destaca-se em primeiro a escolha da profissão. Dora Lice não queria ser professora e crescendo "Entre os folguedos da meninice e os desvelados carinhos dos paes, desabrochara a creança cheia de frescura e crescera em graça e vigor" (LICE, 1928, p. 14), logo teve que lidar com as revezes do destino: "Trazendo o rosto angustiado, entrara seu pae, em casa, um dia. Estava arruinado! A libertação dos escravos lhe havia desorganizado a lavoura. A baixa do café, a par de transações infelizes, lhe levavam a esperança de salvar sua bella e rica propriedade" (idem, p. 18). E, nesse contexto, Hermengarda "Procurando amenizar a rudeza do golpe que ferira o pae, tomou a seu cargo a educação dos irmãos pequenos, trocando, resignada, difícil ofício a si mesma imposto, o sonho que estivera prestes a realizar" (LICE, 1928, p.18). Como preceptora dos irmãos, "Dirigindo tudo com muito método, disciplinara os irmãos como em collegio. As horas das refeições, as do estudo, e do recreio, tudo estava regulado. Quando queriam revoltar-se contra a sua autoridade, sabendo 
Ella que a sciencia de educar é a 'sciencia da razão e do coração', alçava a ternura de irmã e, os pequenos rebeldes se tornavam submissos" (idem, p. 19-20). Reproduzir o que era conhecido das escolas as quais frequentou torna-se, desse modo, a forma segura de conduzir a instrução dos irmãos menores.

Entretanto, apesar do êxito da tarefa pedagógica junto aos irmãos, queria ser médica (e, seu pai antes do duro golpe do destino tinha decidido apoiá-la), mas resigna-se com a ideia, não sem antes protestar veementemente à sugestão feita por um parente:

- Nunca! Nunca serei professora pública! Uma pobre criatura, sempre humilhada, por tantos superiores hierárquicos - diretores, inspetores, secretario. Quero trabalhar sim, não, porém como escrava! Quero trabalhar como um ser pensante, e não como essas infelizes criaturas, transformadas em verdadeiras máquinas, movidas tão somente pela pesadíssima e complicada engrenagem, denominada - Diretoria Geral da Instrução Pública (LICE, 1928, p. 23).

Mas, logo, a jovem seria demovida de sua opinião. A morte do irmão que auxiliava com as despesas da família após a falência do pai e a grande consternação dos mesmos, fez com que Hermengarda repensasse a Escola Normal. Era, a seu pesar, uma ideia fixa. Repelia-a para longe, com repugnância. Ela voltava, recalcitrante, persistente. Era a única taboa salvadora, na sua difícil situação.

O estabelecimento das escolas destinadas ao preparo específico dos professores para o exercício de suas funções está ligado à institucionalização da instrução pública no mundo moderno, ou seja, à implementação das ideias liberais de secularização e extensão do ensino primário a todas as camadas da população. (TANURI, 2000, p. 62)

Resignada, a jovem inscreve-se para os exames de admissão para a Escola Normal e é aprovada plenamente distinguindo-se das demais colegas, aprovadas com distinção, não pelos conhecimentos adquiridos, mas pelas posições sociais privilegiadas que ocupavam. As revelações feitas às diferenças de tratamento entre as candidatas de classes distintas marcam, profundamente, a escrita do texto não somente no processo de formação inicial da jovem Hermengarda, que apesar de excelente estudante e de acertar as respostas não recebe menção honrosa nos seus exames iniciais, mas também na escolha da cadeira (ou escola) para atuar profissionalmente. Nas palavras da protagonista "Só alcançamos alguma cousa por intermédio de políticos" (p. 41). Cabe lembrar que os exames e testes públicos constituem-se uma das primeiras formas legítimas de seleção de professores para atuarem nas escolas públicas da Província de São Paulo.

As escolas normais estão na origem de uma profunda mudança, de uma verdadeira mutação sociológica, do pessoal docente primário. Sob sua ação, os mestres miseráveis e pouco instruídos do início do século XIX vão, em algumas décadas, ceder lugar a profissionais formados e preparados para o exercício da atividade docente (NÓVOA, 1991, p. 125).

Hermengarda apresenta o trabalho docente como função relevante socialmente ${ }^{3}$, mas

\footnotetext{
${ }^{3}$ A discussão acerca da profissão docente e os mecanismos ideológicos que reservam ao magistério um determinado lugar social e o exercício de uma prática pode ser retomada no texto de Regina Zilberman, "Literatura e história da educação: representações do professor na ficção brasileira" publicado em 2004. Neste texto, a autora
} 
que ao mesmo tempo em que tudo é solicitado, muito pouco se tem em troca. Em várias passagens do relato, a autora deixa registrada as injustiças acometidas à sua classe, como no diálogo que estabelece com o jovem inspetor, colega de turma e seu admirador secreto desde os tempos do colégio. O colega, tão logo formado, arranjou-se em um posto na Diretoria de Instrução Pública, segundo o tal admirador, Sr. Aluisio, “- O magistério é uma nobilíssima carreira, mas de todas, a menos independente. Obriga-nos a trazer curvada a fronte." Ao que respondeu prontamente a jovem profissional: "- Pois a minha eu a conservarei sempre erguida!" (LICE, 1928, p. 33), atitude que mantém durante toda a trama e apesar das condições adversas e terríveis de vida e de ofício. As primeiras denúncias estavam aí feitas e relacionavam-se às injustiças sociais percebidas nas melhores classificações escolares e postos de trabalho às jovens provenientes das famílias mais abastadas ou aos homens.

$\mathrm{Na}$ organização/ou manejo das aulas, a professora mantinha a mesma posição altiva, não se deixando abater pelas agruras das escolas longínquas, pela ignorância dos inspetores de ensino, ou ainda pelas dificuldades das estudantes em frequentarem ou aprenderem os conteúdos. E os pais, "satisfeitíssimos com o rápido progresso das filhas, iam pessoalmente, levar-lhe os seus aplausos, e testemunhar-lhe a mais sincera gratidão" (idem, p. 52). E, a professora, "compenetrada da grandeza de sua missão ajudava a criança, flor em botão, a transformar-se em pétalas desabrochadas" (LICE, 1928, p.47).

Tendo um sistema de ensino todo seu, organizava Hermengarda planos de aula que davam ótimos resultados. Lia autores estrangeiros (nada possuíamos em vernáculo, sobre pedagogia e psicologia) e aprendia nelles o que os dirigentes ignoravam. Esforçada, como era, sabia por em prática, com muito proveito para as alunas o que a teoria lhe ensinava (LICE, 1928, p. 46-47).

Um destaque merece ser feito, as metáforas e as comparações que compreendem várias passagens do texto, representativas do discurso da época, nos dão indícios importantes sobre como foram elaboradas as representações de profissão e da carreira docente no início do século XX. De acordo com Israel Scheffler em seu livro "A linguagem da educação" (1974), o estudo dos discursos educacionais, compreendidos nas suas definições, metáforas e slogans, podem ser reveladores dos pressupostos absolutos e relativos que compõem o ideário educacional em diferentes contextos sociais e históricos e merecem atenção para os seus usos e divulgação. Nas palavras do autor,

o discurso educacional abrange inúmeros contextos diferentes, perpassando a esfera científica, a ética e a prática, as quais emprestam uma variedade de matizes e de ênfases a noções que são ostensivamente comuns. (SCHEFFLER, 1974, p.17).

A dedicação da protagonista ao magistério fica patente nas várias páginas do romance, assim como a pouca ou ineficiente formação daqueles que ocupavam cargos de gestão no período social e histórico retratado e, que, por vezes, ao invés de auxiliar atrapalhavam o bom andamento das aulas e o aprendizado das crianças. Não são poucas as referências aos embates travados entre a jovem professora e os inspetores de ensino e os diretores de escola e, dentre esses, ganha destaque o narrado pela autora na sua tão esperada promoção para atuar no grupo escolar. É importante elucidar que a progressão "comum" na carreira docente naquele período, para as professoras sem padrinhos, era atuar por alguns anos em escolas isoladas, para depois

retoma diversas obras da literatura brasileira para analisar as representações da função docente em diferentes momentos da história da escola no Brasil. 
pleitear uma vaga nas escolas reunidas e/ou grupos escolares, considerados a representação da forma mais moderna e organizada de ensino ${ }^{4}$.

Naquele estabelecimento, a protagonista reencontrou na figura do diretor de ensino, o homem que outrora tinha sido copeiro do seu tio. Acostumada com a liberdade para organização dos tempos e dos conteúdos de ensino que tinha na sua escola isolada e com o reconhecimento das estudantes e de seus pais, viu-se no grupo sob responsabilidade do antigo conhecido, condições adversas de atuação profissional. Lecionar em uma escola longínqua e com liberdade ou em um grupo reconhecido e sob a dura fiscalização dos diretores e inspetores de ensino? Tal dúvida acompanhou a protagonista que durante toda a trama transita entre os dois modelos propostos de organização escolar.

\section{As relações conflituosas e o bálsamo da solidariedade profissional: as relações e a constituição dos saberes docentes}

Os desmandos dos diretores de ensino nos dão fortes indícios de que a conformação da docência enquanto profissão reconhecida no âmbito legal e social foi objeto de lutas, resistências e duras acomodações. De acordo com António Nóvoa (1991), os primeiros profissionais da educação tiveram dificuldades para se inserir socialmente, dos mesmos eram requeridos saberes "superiores", nem sempre acompanhados de uma remuneração condizente “[...] Nem burguês, nem notável, nem camponês, nem intelectual, nem artesão, o professor primário tem enormes dificuldades para se inserir socialmente" (NÓVOA, 1991, p. 124).

Das relações conflituosas e áridas com os superiores de ensino, destacam-se outras, mais leves e produtivas do ponto de vista do estabelecimento das redes de sociabilidade e das trocas culturais, possibilitadas com a chegada do novo diretor. "Com a bondade do novo diretor, até as professoras se tornaram mais sociáveis. As casadas recebiam o bloco em reuniões semanais" (LICE, 1928, p. 65). Nessas reuniões, elas cantavam e tocavam piano, declamavam poesias, liam capítulos de livros relacionados ou não ao ofício, debatiam questões educacionais e sobre a vida da mulher na sociedade (discutiram em certa ocasião o feminismo e as diferenças entre os papeis sociais do homem e da mulher), confeccionavam roupas para as crianças pobres pertencentes à caixa escolar do grupo, reunindo, o útil ao agradável.

O universo social e profissional apresentado no enredo é fundamentalmente feminino, a protagonista referencia sempre suas estudantes nas suas aulas, alude a suas amigas professoras, distinguem-se a solidariedade feminina nas relações sociais e apresenta a figura masculina associada ao poder (cargos de gestão e supervisão) e opressão. Essa rede de sociabilidade estabelecida entre as professoras e relatada no romance nos dão indicações importantes de elementos para pensar os saberes associados ao trabalho e aos modos pelos quais as profissionais se unem e se organizam para elaborar as vicissitudes do dia a dia escolar.

Assim como indicam as férteis pesquisas de Maurice Tardif (2002), tão importante quanto os saberes acadêmicos ou disciplinares, os saberes da formação inicial, os saberes curriculares relacionados aos conteúdos a serem ensinados na escola, estão os saberes experienciais, ou seja, aqueles forjados no cotidiano dos professores, compartilhados e

\footnotetext{
${ }^{4}$ Os grupos escolares paulistas, caracterizados pelas escolas graduadas cujo método de ensino é o simultâneo, foram criados em 1893 e marcaram a organização dos sistemas públicos e estatais de ensino, especialmente por estabelecerem alterações relevantes para a organização administrativa e pedagógica da escola primária. Não obstante os grupos terem assumido um caráter modelar, deve-se considerar a diversidade dos estabelecimentos de ensino primário existentes até 1930: escolas-modelo (criadas pela reforma de 1890 para a realização da prática de ensino dos estudantes normalistas), escolas reunidas (cujo número de alunos não era suficiente para se formar um grupo escolar) e escolas isoladas (com um único professor e alunos de diferentes idades e níveis de ensino no mesmo espaço). Além dessas distinções, existem aquelas percebidas entre os estabelecimentos localizados na zona urbana e na zona rural (SOUZA, 1998; GALLEGO, 2003).
} 
refletidos individualmente e pelo grupo que atua em um determinado contexto escolar. São os saberes de vida e da profissão que as mulheres trocam nos momentos das reuniões que permitem o estabelecimento de laços de amizade e solidariedade fundamentais para a superação das condições adversas de vida e de ocupação. "Quando se encontram duas professoras, mormente se dedicadas são ao ensino, versa logo sobre métodos pedagógicos a sua conversação. Hermengarda fizera do magistério um sacerdócio. Não deixava passar ocasião de expender ideias sobre processos de alfabetização" (LICE, 1928, p. 147). Ou ainda, conforme Tardif (2002):

É através das relações com os pares e, portanto, através do confronto entre os saberes produzidos pela experiência coletiva dos professores, que os saberes experienciais adquirem uma certa objetividade: as certezas subjetivas devem ser, então, sistematizadas a fim de se transformarem num discurso da experiência capaz de informar ou de formar outros docentes e de fornecer uma resposta a seus problemas (TARDIF, 2002, p. 52).

O contexto social e histórico descrito e vivenciado por Hermengarda e suas amigas é caracterizado pelo amplo e sistemático debate das questões relacionadas à renovação do ensino. Tópicos como Escola Nova, ensino ativo, método analítico, testes e medidas constituem temas recorrentes nos debates e nas práticas profissionais da época. A literatura pedagógica, composta pelos periódicos especializados e manuais pedagógicos, passa a tratar os problemas educacionais de um ponto de vista técnico, "científico", e a contemplar, desde questões teóricas e práticas do âmbito intraescolar. Destaca-se o deslocamento da preocupação central dos currículos de formação de professores e das escolas primárias dos "conteúdos" a serem ensinados - o que caracterizou os primórdios da instituição - para os métodos e processos de ensino. Aos saberes sobre a identidade profissional somam-se novos relacionados às melhores formas de "manejar a turma" (TANURI, 2000).

A incursão pela obra de Violeta Leme, produzida inicialmente como um texto denúncia das condições aviltantes de vida e de trabalho da professora, torna-se hoje fonte e objeto de estudos para os mais variados temas do campo historiográfico educacional. O recorte proposto aqui pretende trazer elementos para a compreensão do trabalho do/a professor/a, da carreira docente e das contradições presentes em um e outro, mas não esgota de forma alguma a análise dessas questões, nem o potencial formativo e formador do texto. Por meio da sua leitura, é possível compreender a vida da professora, suas relações com outros profissionais hierarquicamente superiores, com as suas colegas e estudantes sob sua responsabilidade, assim como com os saberes práticos da sua profissão.

\section{Considerações finais}

Quando escrevi O Quinze, entre 1929 e 1930, já era jornalista profissional. Foi então também que tive o único emprego público da minha vida: fui nomeada interinamente professora da Escola Normal professora de história - ganhando quatrocentos mil réis por mês, o que era um ordenado razoável nessa época (QUEIROZ \& QUEIROZ, 2004, p. 31).

Voltando um pouco atrás: diplomei-me professora em 1925, com quinze anos (QUEIROZ \& QUEIROZ, 2004, p. 41). 
A análise conjunta de $O$ calvário de uma professora e Clarissa realçou outras nuances da história da formação docente, numa época em que o tema da educação para o desenvolvimento dos indivíduos e o progresso da nação alcançou grande evidência no discurso educacional brasileiro. Em suas aproximações como Bildungsroman, os romances permitem imaginar o que significava para uma jovem mulher formar-se professora por volta dos quinze anos - como foi o caso da escritora cearense Rachel de Queiroz e tantas mulheres de sua geração - e assumir o encargo de conduzir o desenvolvimento das crianças no período em que a escola pública estava em processo de consolidação e expansão pelo território brasileiro e a inserção profissional das mulheres ainda era incipiente e, para a grande maioria, restringia-se a poucas alternativas, dentre as quais o ensino primário.

O calvário de uma professora proporciona um relato vívido das adversidades enfrentadas pelas jovens recém-saídas das escolas normais durante o primeiro período republicano: a distância que precisava ser vencida para se chegar ao trabalho, a precariedade das instalações da escola, a escassez de materiais didáticos e de publicações sobre educação em português, a arbitrariedade daqueles que exerciam os cargos de autoridade etc. A protagonista denunciava ainda a corrupção, nas práticas de favorecimento de protegidas dos políticos na distribuição dos cargos, entre outras dificuldades, percebidas como ainda mais amargas porque ela não desejara abraçar a carreira docente, mas foi obrigada a isso. Apesar de tudo, ela apreciava os encantos da profissão no "desabrochar" de suas alunas e desempenhava o ofício com inteligência e responsabilidade.

Clarissa, por sua vez, pode ser lido como a expressão literária das esperanças depositadas no futuro da escola a partir da década de 1930, ameaçadas apenas pela persistência do ensino tradicional que ensombrecia a existência da jovem professora no momento em que ela atravessava o portão do colégio. Em oposição ao ensino desinteressante porque apartado de seu cotidiano e de suas inclinações, eram as experiências vividas fora do colégio, as observações e reflexões que fazia a partir do seu entorno que lhe proporcionavam os aprendizados mais relevantes sobre o mundo e sobre si mesma.

Consideramos que a aproximação dessas narrativas na análise realizada permitiu entrever a fertilidade das obras literárias como fontes para a história da educação, quando examinadas em articulação com a produção acadêmica.

\section{Referências}

BAKHTIN, Mikhail. Estética da criação verbal. São Paulo: Editora WMF Martins Fontes, 2011.

BASTOS, Maria Helena Camara; CUNHA, Maria Teresa Santos. Olhai o que o Tempo não Levou. A Literatura de Érico Verissimo. In GONÇALVES, Robson Pereira (org.) O Tempo e o Vento: 50 anos. Santa Maria, RS: UFSM; Bauru, SP: EDUSC, 2000.

BASTOS, Maria Helena Camara; STEPHANOU, Maria. Infância, Higiene \& Educação. Trabalho Apresentado na 28 . Reunião da ANPEd (Associação Nacional de Pós-Graduação e Pesquisa em Educação) GT 02 - História da Educação. Caxambu, MG, 2005.

BOSI, Alfredo. História concisa da literatura brasileira. São Paulo: Editora Cultrix, 1997. BOURDIEU, Pierre. Os usos sociais da ciência - por uma sociologia clínica do conhecimento científico. São Paulo: Unesp, 2004.

BOURDIEU, Pierre. A ilusão biográfica. In: FERREIRA, Marieta de Morais; AMADO, Janaina. Usos e abusos da história oral. Rio de Janeiro: Editora da FGV, 1998, p. 183-191. 
BENJAMIN, Walter. Magia e técnica, arte e política: ensaios sobre literatura e história da cultura. São Paulo: Brasiliense, 1994.

CARVALHO, Marta Maria Chagas de. A escola e a república. São Paulo: Brasiliense, 1989.

CATANI, Denice Barbara; BUENO, Belmira Amélia Oliveira; SOUSA, Cynthia Pereira; SOUZA, Maria Cecilia Cortez (org.) Docência, Memória e Gênero: estudos sobre formação. São Paulo: Escrituras Editora, 1997.

FERREIRA, António; GONDRA, José. Idades da vida, infância e a racionalidade médicohigiênica em Portugal e no Brasil (séculos 17-19). Revista Brasileira de Estudos Pedagógicos, v.87, n.216, 2006, p.119-134. DOI: https://doi.org/10.24109/2176-6681.rbep.87i216.789

FREIRE, Maria Martha de Luna. 'Ser mãe é uma ciência': mulheres, médicos e a construção da maternidade científica na década de 1920. História, Ciências, Saúde-Manguinhos, Rio de Janeiro, v.15, supl., p.153-171, jun. 2008. DOI: https://doi.org/10.1590/S0104-59702008000500008

GALLEGO, Rita de Cássia. Uso(s) do tempo: a organização das atividades de alunos e professores nas escolas primárias paulistas (1890-1929). Dissertação de Mestrado. São Paulo: FEUSP, 2003.

KÜTTER, C. A. Bildungsroman feminino: uma leitura de Balada de amor ao vento, de Paulina Chiziane. Literatura e Sociedade, v.23, n.27, p.196-216, 2018. Disponível em: https://www.revistas.usp.br/ls/article/view/148543. Acesso em: 14 maio 2021. DOI: https://doi.org/10.11606/issn.2237-1184.v0i27p196-216

LUKÁCS, Gerg. A teoria da romance: um ensaio histórico-filosófico sobre as formas da grande épica. São Paulo: Duas cidades;Editora 34, 2000.

LICE, Dora. O calvário de uma professora. São Paulo: Estabelecimento Gráfico Irmãos Ferraz, 1928.

MANIFESTO DOS PIONEIROS DA EDUCAÇÃO NOVA (1932). Fernando de Azevedo (et al.) Recife: Fundação Joaquim Nabuco, Editora Massangana, 2010.

MORAES, Dislane Zerbinatti. Literatura, memória e ação política: uma análise de romances escritos por professores paulistas. Dissertação de Mestrado. São Paulo: FEUSP, 1996.

MORAES, Dislane Zerbinatti. Violeta Leme Fonseca (Dora Lice): a biografia de uma professora a contrapelo do seu legado literário. In: Mulheres inovadoras no ensino: (São Paulo, séculos XIX e XXI). Belo Horizonte: Fino Traço, 2019.

MORAIS, Roselusia Teresa Pereira de. Representações da docência em romances de Érico Veríssimo: a personagem Clarissa. 2010. Dissertação (Mestrado). Universidade Federal de Pelotas, Pelotas.

NAGLE, Jorge. Educação e Sociedade na Primeira República. São Paulo: EPU/Edusp, 1976. NÓVOA, A. Para o estudo sócio-histórico da gênese e desenvolvimento da profissão docente. Teoria \& Educação.n.4, p.109-139, 1991. 
PINTO, Cristina Ferreira. O Bildungsroman feminino: quatro exemplos brasileiros. São Paulo: Perspectiva, 1990.

QUEIROZ, Rachel de; QUEIROZ, Maria Luíza de. Tantos anos. 4ª ed., São Paulo: Arx, 2004.

SANTOS, Donizeth. O projeto literário de Érico Verissimo. Estudos de Literatura Brasileira Contemporânea. Brasília. n.44. p.331-363, jul./dez., 2014. DOI: https://doi.org/10.1590/2316-40184416

SCHEFFLER, Israel. A linguagem da educação. BARBOSA FILHO, Balthazar (trad.). São Paulo: Editora da Universidade de São Paulo, 1974.

SEVCENKO, Nicolau. Literatura como missão: tensões sociais e criação cultural na Primeira República. São Paulo: Brasiliense, 1983.

SOUZA, Rosa Fátima. Templos de Civilização: A Implantação da Escola Primária Graduada no Estado de São Paulo (1890-1910). São Paulo: Fundação Editora da UNESP, 1998.

TANURI, Leonor. "História da formação de professores". Revista Brasileira de Educação, no. 14 , mai/ago. 2000 , p. 61-88.

TARDIF, Maurice. Saberes docentes e formação profissional. $4^{\text {a }}$ Ed. Rio de Janeiro: Vozes, 2002.

TEIXEIRA, Anísio. A pedagogia de Dewey. Estudo introdutório. IN:DEWEY, John. Vida e Obra. São Paulo: Edições Melhoramentos, 1965.

VERÍSSIMO, Érico. Caminhos cruzados. São Paulo: Companhia de Bolso, 2019.

VERÍSSIMO, Érico. Saga. São Paulo: Companhia das Letras, 2006.

VERÍSSIMO, Érico. Música ao longe. São Paulo: Companhia das Letras, 2005.

VERÍSSIMO, Érico. Clarissa. Porto Alegre: Editora Globo, 1976.

VERÍSSIMO, Érico. Um lugar ao sol. Porto Alegre: Editora Globo, 1976.

VIDAL, Diana Gonçalves. 80 anos do Manifesto dos Pioneiros da Educação Nova: questões para debate. Educação e Pesquisa [online]. 2013, vol.39, n.3, pp.577-588. DOI: https://doi.org/10.1590/S1517-97022013005000007

VIDAL, Diana Gonçalves. Escola Nova e processo educativo. In: LOPES, Eliane Marta Teixeira; FARIA FILHO, Luciano Mendes; VEIGA, Cynthia Greive (Orgs.) 500 anos de educação no Brasil. Belo Horizonte: Autêntica, 2010.

ZILBERMAN, Regina. "Literatura e história da educação: representações do professor na ficção brasileira". História da Educação ASPHE/FaE/UFPel. Pelotas, no. 15, 2004, p. 73-87. 